\title{
Distribution Of CD4+RORg-T Th17 And CD25+ FOXP3+ Treg In Leprosy Patient With Reversal Reaction
}

\author{
Renni Yuniati ${ }^{1}$, Riawan $W^{2}$, Widasmara $D^{3}$, Darmaputra IGN $^{4}$, Arifin $\mathrm{S}^{2}$ \\ ${ }^{1}$ Department of Dermatology and Venereology Faculty of Medicine Diponegoro University, Semarang, \\ Indonesia. \\ ${ }^{2}$ Department of Biochemical-Biomolecular, Faculty of Medicine Brawijaya University, Malang, Indonesia. \\ ${ }^{3}$ Department of Dermatology and Venereology, Faculty of Medicine Brawijaya University, Malang, Indonesia. \\ ${ }^{4}$ Department of Dermatology and Venereology, Faculty of Medicine Udayana University, Sanglah, Indonesia.
}

\section{Article Info}

History:

Received : 06 Nov 2017

Accepted : 27 Dec 2017

Available: 31 Dec 2017

\begin{abstract}
Background: One of the most common difficulties found in leprosy management is how to manage leprosy reaction, even though MDT has proven to be effective for the patients. Reversal reaction is associated with cell mediated immunity (CMI), consists of T-helper (Th) 1 and Th2 activities. Moreover, subset of CD4+ Th17 and CD25+ FOXP3 Treg were known to have an important role in leprosy's natural history. Prior study showed a decreasing number of CD25+ FOXP3 Treg and increasing number of CD4+ Th17 in type II reversal reaction (ENL). However, the distribution of Th17 and Treg in type I reversal reaction (RR) has not yet been identified.

Objective: To compare the distribution of CD4+ Th17 and CD25+ FOXP3 Treg between RR and ENL patient groups.

Method: A total of 50 samples, consisted of 27 samples of reversal reaction (RR) and 23 samples of ENL, were collected. Observation of CD4+ RORg-T Th 17 and CD25+ FOXP3 Treg were conducted with immunohistochemistry staining technique using anti FOX-P3 and anti RORg-T. Expression of CD4+ ROR-g Th17 and CD25+ FOXP3 Treg in percentage were analy zed using T-test.

Result: There is a significant difference in mean CD4+ ROR-g Th17 and IL17 cell distribution for RR patient group (14.96\% and 10.72\%) compared with ENL (9.12\% and $4.28 \%)$. No significant difference were found between mean CD25+ FOXP3 Treg and TGF- $\beta$ cell distribution in RR patient group $(6.12 \%$ and $5.44 \%)$ compared with ENL group (6.16\% and 5.96\%).

Conclusion: There is a significant increment od CD+RORg-T Th17 and IL17 in RR patients group compared with ENL patients group. however, the distribution of CD25+ FOXP3+ Treg and TGF beta in RR has no significant difference campared with ENL.
\end{abstract}

Keywords: CD4+RORg-T Th17, CD25+ FOXP3+ Treg, IL17, TGF- $\beta$, Reversal Reaction, Erythema Nodosum Leprosum

\section{INTRODUCTION}

Leprosy is a frightening disease for community which cause ulceration, mutilation, and deformities to the patients. The disease has variety of manifestations depend on patient's immune response towards the infection. Two key purposes from leprosy management are recovery and disability prevention from the disease. WHO recommended a Multi Drug
Therapy (MDT) consists of rifampicin and dapsone for PB leprosy, and rifampicin, dapsone, and clofazimine to treat MB leprosy. Therapy is given for 6 months duration for PB leprosy and 12 months duration for MB leprosy. MDT has been proven effective to eradicate $M$. leprae in most of the patients. ${ }^{1}$ Even though it has been proven effective, 
* Corresponding author:

Renni Yuniati

Telp./Fax:

E-mail: renniyuniati@yahoo.com

the most difficult issue in leprosy management is to manage the leprosy reaction.

Leprosy reaction is caused by patient's immunological dynamic response to $M$. leprae which could happen before, during, and after MDT administration. ${ }^{2}$ This reaction is an acute episode of the disease with constitutional symptoms, activation, sometimes accompanied with new skin efflorescence. Two types of leprosy reaction are type 1, known as reversal reaction ( $R R)$, caused by acute changes in cellular immunity, and type 2 reaction known as erite ma nodosum leprosum (ENL), caused by humoral immunity process. ${ }^{3}$ Reversal reaction is associated with cell mediated immunity (CMI) activities, consists of T-helper cell (Th1) and (Th2). It is characterized with granuloma expansion, edema, CD4+ recru itment, increasing IL-2, IL-10, and IL-12 receptors, and expression of human leukocyte antigens-D in cellular infiltrate. ${ }^{4}$

Another CD4+ Th subset that shows divergence in leprosy is the Th17 populationassociated with inflammation. ${ }^{5}$ The Th17 subset is highest in healthy contacts exposed to the diseases compared with patients, indicating its importance in innate immunity. ${ }^{6,7}$ Th17 cells appeared in the leprosy patients who showed non-polarised Th0 subset. $^{6}$ Therefore it would appear that Th17 plays a role in the immune responses to $M$. leprae infection and may be an alternate pathway for bacillary clearance both in the early and later stages of infection. The associated chemokines may help in its migration to lesional sites.

Another distinct lineage of $\mathrm{T}$ cells that has exciting implications for dampening inflammatory responses is the $\mathrm{T}$ regulatory cell (Treg), which has a CD4+CD25+ nuclear FOXP3+ phenotype and shares a similar differentiation pathway to Th17 cells, although they have opposite effects.Several types of Tregs have been described; some are natural Tregs derived from the thymus and act via contact with target cells. ${ }^{8}$ Others are inducible and mediate inhibition through cytokines such as transforming growth factor- $\beta$ (TGF- $\beta$ ) and IL-10 (induced Treg [iTreg]). ${ }^{9}$ Transcription factor FOXP3 is thought to be the primary requirement for the suppressive function, though low and transient expression has been reported in activated human $\mathrm{T}$ cells with and without suppress or function. Though Tregs in mice express CD25 constitutively, in humans only those with CD25 show suppressive function. ${ }^{10}$

Leprosy reactions in contrast showed a decrease in Treg cells which paralleled the increase in Th 17 population. ${ }^{11}$ Moreover, there was downregulation of intracellular TGF- $\beta .^{11,12}$ Most reports showed a reduction in Treg cells in patients with ENL reactions compared with non-reaction L-lep counterparts. Akan tetapi pada reaksi kusta tipe I (RR) bagaimana distribusi Th17 dan Treg masih belum jelas. ${ }^{11,12}$ However, in type I leprosy reaction (RR), the distribution of Th17 and Treg has not yet been identified. Thus, this study aimed to compare the distribution between Th17 and FOXP3 Treg in RR and ENL patient groups.

\section{MET HOD}

A total of 50 samples were used in this study, consisted of 27 samples of RR patients and 23 samples of ENL patients. The samples were collected from outpatient clinic in Donorojo Hospital and Ministry of Health in Jepara from June 2014-August 2014. Patients were 20-60 years old and had agreed to sign the standard informed consent from Ethical Committee of Airlangga University.

Biopsy samples were collected at the lesion area or lower arm extensor side. Then, the area was disinfected with alcohol $70 \%$ and local anesthetic Lidocaine $0.25 \mathrm{ml}$ was administered subcutaneously near the biopsy area. Biopsy were conducted using punch method with diameter of $3 \mathrm{~mm}$. Tissue sample was inserted to a $1.5 \mathrm{ml}$ tube filled with formalin $10 \%$. The after-biopsy skin was cleaned using $\mathrm{NaCl}$ $0.9 \%$, then topical antibiotic fusidic acid was applied and the skin was covered with sterile gauze. The sample underwent a fixation and processed in paraffin. Microscopic slide was made using rotary microtome with $4 \mu \mathrm{m}$ slicing. Staining with Hematoxylin-Eosin was applied to confirm the structure and leprosy type. Observation of CD4+ RORg-T Th17 and C25+ FOXP3+ Treg were using immunohistochemistry single staining technique with anti-FOX-P3 anti RORg-T retrieved from Santa Cruz Biotech (USA) and immunohistochemistry kit of DBio Sys Immunostaining Kit (Netherland). The staining result was then photomicrographed using Niokon E-100 Microscope with ICLEA7 Sony Camera 400x magnification, then expression analys is was done using immunoratio software (Freeware). Percentage of expression CD4+ RORg-T Th17 and $\mathrm{C} 25+\mathrm{FOXP} 3+$ Treg were inserted to table and analyzed using T-test in IBM-SPSS 21 for W indows.

\section{RES ULT}

In this study, there were 27 samples of RR patients and 23 patients of ENL patiens. Each cases were classified based Hematoxy lin-Eosin (HE) staining microscope examination, as the figure below.

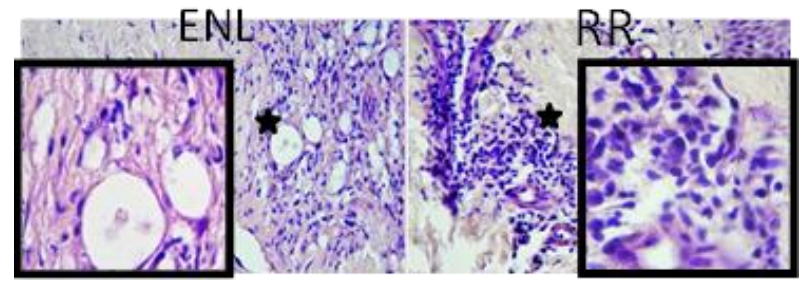

Figure 1. ENL: Granulomatous infiltrate of vacuolated macrophages and neutrophils in the dermis. RR: Influ xof mononuclear phagocytes with epithelioid differentiation. Hematoxylin- eosin staining; original magnification $\mathrm{x} 200$ and $\mathrm{x} 1000$ inserted. 
Expression of FOXP3, RORg-T, TGFb 1 and IL-17 are described below:

ENL

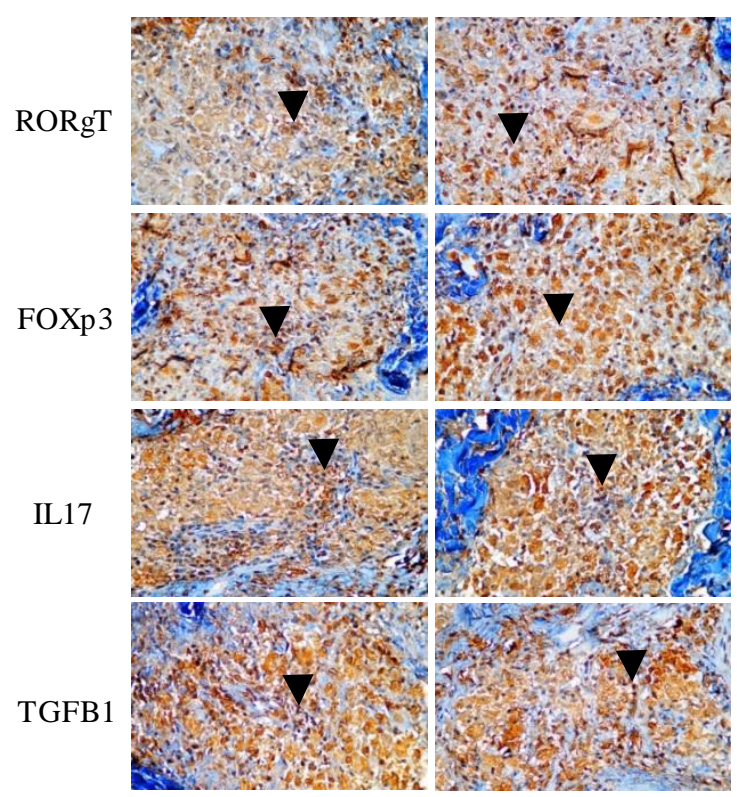

Figure 2. Immunohistochemistry staining for Foxp3, RORgT, TGFb1 and IL17A from biopsy samples of RR and ENL patients. Photomicrograph showing (Orig inal magnification:400×) RORgT and FOXp3 cells positive in brown color (arrow).

Immunohistochemistry study result showed a significant difference in mean CD4+RORg-T Th 17 and IL17 cell distribution in RR patient group (14.96\% and $10.72 \%$ ) compared with ENL patient group $(9.12 \%$ and $4.28 \%)$. However, no significant difference in mean CD25+ FOXP3+ Treg and TGF- $\beta$ cell distribution in RR patient group $(6.12 \%$ and $5.44 \%)$ compared with ENL patient group $(6.16 \%$ and $5.96 \%)$.

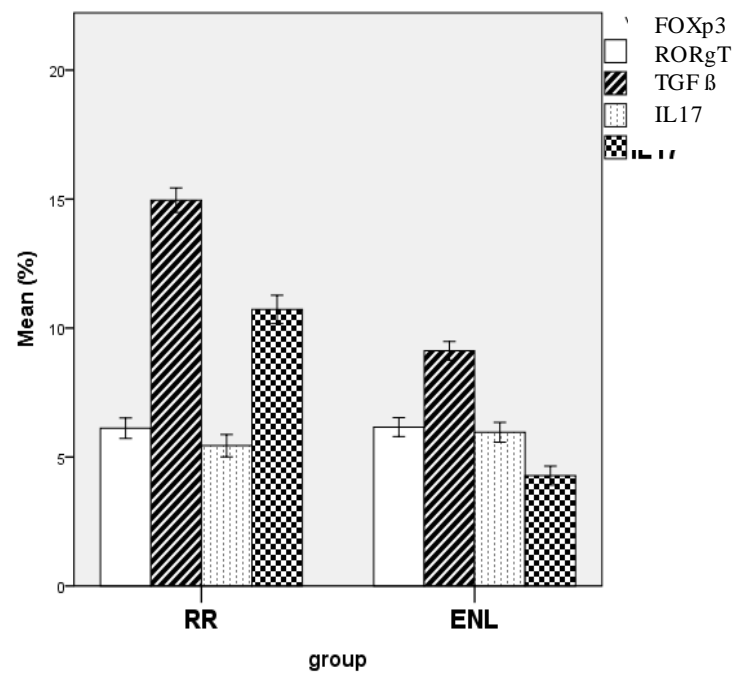

Graphic 1. Mean FOXP3, RORgT, TNF $\alpha$ dan IL17 percentage in RR and ENL patient group. We found a significant difference in CD4+RORg T Th17 and IL17 in RR patient group (14.96\% and $10.72 \%$ ) compared with ENL patient group (9.12\% and $4.28 \%$ ).

\section{DISCUSS ION}

In this study, expression of FOXP3+ was evaluated from the skin with $\mathrm{T}$ lymphocyte infiltrate. We found that Treg cells were produced in reactive state (either type I or II). Treg cell has an important role in controlling the overactive immune response towards microbe's antigen, especially pathogens which caused persistent infection in this study. Prior study has explained a significant decrement of FOXP3+ Treg in ENL compared with stabilized leprosy patients, although it was not found in RR patients. ${ }^{2}$ In this study, we found FOXP3+ Treg in all skin specimens of RR and ENL with a low number. From all of the case, positive FOXP3 cell was strongly related with epithelioid or macrophage, showing a functional interaction between Treg and histiocyte. We observed no statistically significant differences between FoxP3 + Treg cells between type I reaction (RR) and type II reaction (ENL), even the number is almost the same.

Other study showed that CD+FOXP3+ T-Reg cell produced TGF- $\beta$ and increased in stabilized lepromatous patients and also could explain issues with this type of leprosy. ${ }^{11}$ our study showed that TGFb 1 occurred in type I leprosy reaction (RR) and type II (ENL), where the presentation tends to be lower in RR thatn ENL, but this is not statistically significant.

This study emphasized an inhibition of FOXP3 cell expression and also TGF- $\beta$ in RR condition compared with ENL, which related to an unresponsiveness of $\mathrm{T}$ cell observed in RR patients. One interesting finding in this study is an increasing RORgT Th17 positive cells found in RR leprosy compared with ENL patients, and it was statistically significant. Also, RR patients showed a higher IL17A expression than ENL patients.

The present study was undertaken with a view to understanding the inflammation and or immunopathology seen in patients under going episodes of leprosy reactions which are a cause of severe morbidity and nerve damage. Previous studies had shown that Th17 cells formed a third subset in leprosy and were seen in stable leprosy patients in the absence of Th1 and Th2 polarization. ${ }^{11}$ Our study showed a disturbed equilibrium between Th17 cells and Treg cells in leprosy reaction, especially increased Th17 cells and decreased Treg cells in number. This imbalance was mediated by cytokines, showed by decreasing TGF- $\beta$ number in the same time. Increasing Th17 activities with IL-17A expression would explain the inflammatory and immunopathology process caused by leprosy reaction.

Overall, our results provide some evidence to the hypothes is that, in T1R, downmodulation of Tregs cells would favor the development of Th-17 responses that characterize this type of reaction. We thus believe that better understanding of the role played by Tregs cells in reaction episodes can possibly provide a new target for the treatment of this still-challenging complication of leprosy. 


\section{REFERENCES}

1. WHO Expert Committee on leprosy. Eight report. Geneva, World Health Organization, 2002 (W HO Technical Report Series, No. 968).

2. Worobec SM. 2012. Current Approaches and Future Directions in The Treatment of Leprosy. Tropical Medicine 3:79-91.

3. Walker SL, Lockwood DNJ. (2006). The Clinical and Immunological Features of Leprosy. from: http://bmb.oxfordjournals.org/content/7778/1/103.full.pdf+ht ml, 2014 Jan 4.

4. Pandhi D, Chhabra N. 2013. New Insights in The Pathogenesis of Type 1 and Type 2 Lepra Reaction. Indian J Dermatol Venereol Lepro179(6):739-749.

5. Bettelli $\mathrm{E}$ et al. $\mathrm{T}(\mathrm{H})-17$ cells in the circle of immunity and autoimmunity. Nat Immunol. 2007;8(4):345-50.

6. Saini C et al. CD4+ Th 17 cells discriminate clinical types and constitute a third subset of non Th1, Non Th2 T cells in human leprosy. PLoS Neg1 Trop Dis. 2013; 7(7):e2338.

7. Sadhu S et al. Reciprocity between Regulatory T Cells and Th17 Cells: Relevance to Polarized Immunity in Leprosy. PLoS Negl Trop Dis. 2016;10(1): e0004338.

8. Abbas $\mathrm{AK}$ et al. Regulatory $\mathrm{T}$ cells: recommendations to simplify the nomenclature. Nat Immuno 1. 2013;14(4): 307-8.

9. Josefowicz SZ et al. Regulatory $\mathrm{T}$ cells: mechanis $m s$ of differentiation and function. Annu Rev Immunol. 2012;30: 531-64.

10. Nath I et al. Natural suppressor cells in human leprosy: the role of HLA-D-identical peripheral lymphocytes and macrophages in the in vitro modulation of ly mphoproliferative responses. Clin Exp Immunol. 1980;42(2):203-10.

11. Saini C et al. Leprosy Reactions Show Increased Th17 Cell Activity and Reduced FOXP3+ Tregs with Concomitant Decrease in TGF-beta and Increase in IL-6. PLoS Negl Trop Dis. 2016;10(4):e0004592.

12. Vieira AP et al. Development of Type 2, But Not Type 1, Leprosy Reactions is Associated with a Severe Reduction of Circulating and In situ Regulatory T-Cells. Am J Trop Med Hyg. 2016;94(4):721-7. 